\section{Mcl-1 deficiency results in peri-implantation embryonic lethality}

\author{
Julie L. Rinkenberger, ${ }^{1}$ Susan Horning, ${ }^{1}$ \\ Barbara Klocke, ${ }^{1}$ Kevin Roth, ${ }^{1}$ \\ and Stanley J. Korsmeyer ${ }^{1-3}$
}

\begin{abstract}
${ }^{1}$ Departments of Medicine and Pathology, Howard Hughes Medical Institute, Washington University School of Medicine, St. Louis, Missouri 63110 USA; $^{2}$ Dana-Farber Cancer Institute, Harvard Medical School, Boston, Massachusetts 02115 USA
\end{abstract}

We disrupted the Mcl-1 locus in murine ES cells to determine the developmental roles of this Bcl-2 family member. Deletion of $\mathrm{Mcl}-1$ resulted in peri-implantation embryonic lethality. $\mathrm{Mcl-1}^{-/-}$embryos do not implant in utero, but could be recovered at E3.5-4.0. Null blastocysts failed to hatch or attach in vitro, indicating a trophectoderm defect, although the inner cell mass could grow in culture. Of note, $\mathrm{Mcl-1}^{-/-}$blastocysts showed no evidence of increased apoptosis, but exhibited a delay in maturation beyond the precompaction stage. This model indicates that $\mathrm{Mcl}-1$ is essential for preimplantation development and implantation, and suggests that it has a function beyond regulating apoptosis.

Received October 8, 1999; revised version accepted November 19, 1999.

MCL-1 was identified in a screen for differentiation-induced genes activated in the human monocytic leukemia cell line, ML-1 (Kozopas et al. 1993). The MCL-1 protein is a member of the BCL-2 family displaying all four of the BCL-2 homology domains (BH1-4) and has been localized to intracellular membranes, particularly the mitochondrial membrane (Kozopas et al. 1993; Yang et al. 1995). MCL-1 is widely expressed in human and murine tissues and cell lines as well as in a wide variety of human tumors (Kozopas et al. 1993; Krajewski et al. 1994, 1995). MCL-1 has been shown to delay cell death in selected cell lines, but in comparison, is not as potent as BCL-2, and has no effect in other systems in which BCL-2 proves protective (Reynolds et al. 1994, 1996; Bodrug et al. 1995; Zhou et al. 1997). Transgenic mice that overexpressed Mcl-1 displayed improved hematopoietic cell survival and enhanced outgrowth of myeloid cell lines (Zhou et al. 1998). MCL-1 expression has been noted to be rapidly up-regulated in response to certain cytotoxic and differentiation stimuli, but the increased expression is often transient (Yang et al. 1996). These

[Key Words: Mcl-1; apoptosis; implantation; embryo; blastocyst; Bcl-2 family]

${ }^{3}$ Corresponding author.

E-MAIL stanley_korsmeyer@dfci.harvard.edu; FAX (617) 632-6401. results indicated that MCL-1 functions to inhibit apoptosis in selected cell types but do not exclude that MCL-1 could possess other nonapoptotic functions.

Whereas multiple BCL-2 family members are often coexpressed in the same tissues, evolving evidence indicates a selectivity in their participation following specific death or survival signals. For example, although multiple proapoptotic members are present in superior cervical ganglion (SCG) cells, BAX is singularly required for their death following NGF deprivation (Deckwerth et al. 1996). Conversely, it is the proapoptotic BAD molecule that is inactivated by phosphorylation following exposure to the IL-3 survival factor (Zha et al. 1996). Mice deficient for individual family members also support distinct roles for each member. Bcl-2 knockout mice proved viable but fail to maintain homeostasis with dramatic apoptosis of $\mathrm{B}$ and $\mathrm{T}$ lymphocytes and melanocytes. A loss of nephron units during embryogenesis manifests as polycystic kidney disease postnatally (Veis et al. 1993). Bcl-X-deficient mice are embryonic lethal with massive hematopoietic and neuronal cell death (Motoyama et al. 1995). Knockouts of the proapoptotic Bax (Knudson et al. 1995) as well as the antiapoptotic Bcl-w gene (Print et al. 1998; Ross et al. 1998) each manifest as testicular degeneration and male sterility. Consequently, we elected to generate an Mcl-1-deficient mouse to identify the tissues in which Mcl-1 is most critical and to gain further insight into its functional role.

\section{Results and Discussion}

We constructed a deletional targeting vector for Mcl-1 that eliminates most of exon I including the initiation codon (Fig. 1A). Subsequent chimeric mice transmitted the disrupted Mcl-1 to the germ line. Mcl-1 ${ }^{+/-}$heterozygous males and females were grossly and microscopically normal and fertile. Matings of heterozygotes on C57BL/6 and 129Sv/J backgrounds produced 529 pups; $67.5 \%$ were $\mathrm{Mcl}^{-1^{+/-}}$, but none were $\mathrm{Mcl}^{-1^{-/}}$homozygous nulls (Fig. 1b).

A nested PCR strategy (Fig. 1a) was developed to genotype embryos (Fig. 1c). Timed pregnancies of Mcl-1 heterozygote matings were analyzed at E7.5-13.5 of gestation. No Mcl-1 null pups were observed at any of these time points (Table 1). Dissection of embryos from implantation sites at E7.5 as well as histologic sections of uteri at E5.5 and E6.5 revealed no evidence of embryo resorption or empty decidua (not shown). A normal mouse blastocyst attaches to the uterus between E4.5 and E5.0 (Rinkenberger et al. 1997). Even embryos that die or are degraded shortly after attachment stimulate decidualization, a process whereby stromal cells expand, elaborate extracellular matrix, and form tight junctions (Welsh 1993). Consequently, we isolated and genotyped preimplantation embryos from timed heterozygote matings. Mcl-1 null blastocysts and morula were identified, although the lower than expected frequency $(16 \%)$ sug- 

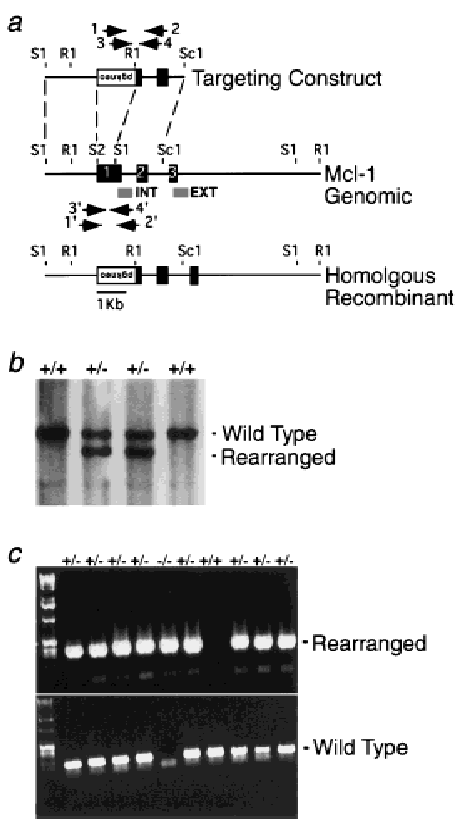

Figure 1. (a) Map of the Mcl-1 murine genomic locus and targeting vector. Exons are indicated by black boxes, and positions of internal and external probes are represented by gray boxes; PCR primers are denoted by arrows. The $p g k-n e o$ cassette is inserted in the opposite transcriptional orientation and replaces a SacII (S2) to SacI (S1) fragment of exon I containing the translation start site. EcoRI (R1), ScaI (Sc1). (b) Representative genomic blot probed with the external probe. A wild-type 12-kb EcoRI fragment is recognized; the rearranged homologous recombinant allele is $10-\mathrm{kb}$. (c) Representative nested PCR genotyping results from preimplantation embryos. The paired primers distinguished a 350-bp rearranged fragment of the homologous recombinant allele from a 168-bp fragment of the wild-type allele.

gested Mcl-1 deficiency had impaired development by this stage (Table 1).

To determine the expression pattern of $\mathrm{Mcl}-1$ at preimplantation time points, we performed RNA in situ

Table 1. Genotypes of embryos from heterozygous matings

\begin{tabular}{lrrrc}
\hline \multirow{2}{*}{$\begin{array}{l}\text { Freshly isolated } \\
\text { embryos from } \\
\text { gestational day }\end{array}$} & \multicolumn{5}{c}{\begin{tabular}{c} 
Genotype \\
\cline { 2 - 5 }
\end{tabular}} & \multicolumn{1}{c}{$+/+$} & $+/-$ & $-/-$ & not determined \\
\hline $13.5-14.0$ & $4(25)$ & $12(75)$ & 0 & 0 \\
9.5 & $6(25)$ & $13(54)$ & 0 & $5(21)$ \\
7.5 & $11(24)$ & $31(69)$ & 0 & $3(7)$ \\
$4.0^{\star}$ & $18(30)$ & $27(44)$ & $10(16)$ & $6(10)$ \\
\hline
\end{tabular}

Embryos

cultured on

\begin{tabular}{lrrrr}
\hline MEFs & & & & \\
attached & 6 & 15 & 0 & 0 \\
$\quad$ nonattached & 8 & 0 & 1 & 6 \\
Vitronectin & & & & 2 \\
attached & 24 & 30 & 0 & 33 \\
nonattached & 9 & 17 & 10 & \\
\hline
\end{tabular}

a Preimplantation morula- and blastocyst-stage embryos. hybridization on sections of wild-type embryos (Fig. 2). Mcl-1 was expressed in both morula and blastocysts and was present in both trophectoderm (TE) and inner cell mass (ICM) (Fig. 2a,b), whereas the control sense probe exhibited no hybridization signal above background (Fig. 2c). Mcl-1 null blastocysts, which approached the expected frequency from heterozygote matings, lacked a hybridization signal with the antisense probe (Fig. 2d). Most Mcl-1 null blastocysts, whether identified by RNA in situ or PCR genotype, were morphologically indistinguishable from wild-type blastocysts (not shown). However, a subset of null embryos isolated at E4.0 exhibited delayed maturation resembling a precompaction 8- to 16-cell blastomere stage embryo instead of a morula or blastocyst (Fig. 2e). This apparent arrest of Mcl-1 null embryos by the blastomere stage became consistent as
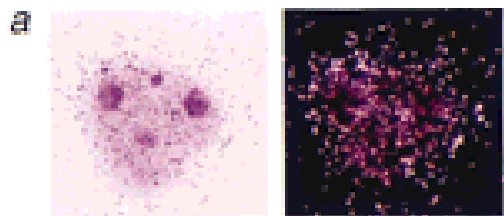

b
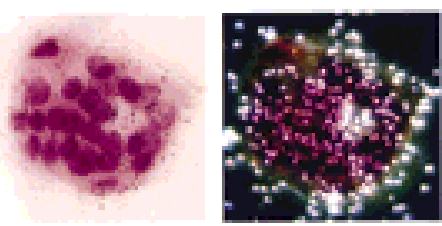

$c$
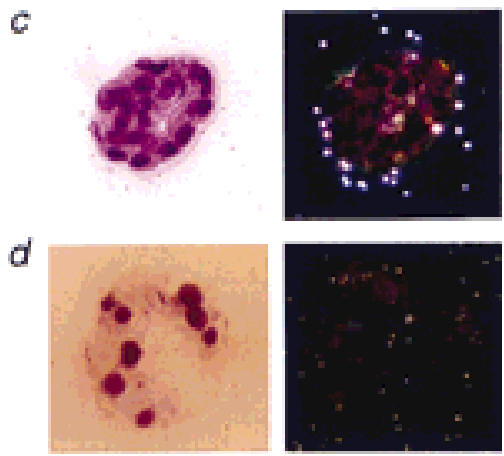

e

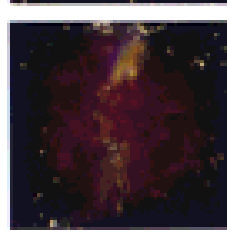

Figure 2. Representative Mcl-1 RNA in situ hybridization results on preimplantation embryos. (a) Light- and dark-field images of a morula stage wild-type embryo hybridized with the Mcl-1 anti-sense probe. (b) Light- and dark-field images of a blastocyst stage wild-type embryo with the Mcl-1 antisense probe revealing signal in both TE and ICM. (c) The Mcl-1 sense probe hybridized to wild-type blastocyst displayed no signal above background. (d) Light- and dark-field image of an Mcl-1 null blastocyst hybridized with the Mcl-1 antisense probe. (e) Representative noncompacted blastomere stage Mcl-1 null embryo that fails to hybridize with the Mcl-1 antisense probe. Magnification, $400 \times$. 
the mice were crossed further onto a C57BL/6 background.

Mcl-1 RNA in situ hybridization was also performed on fixed sections through blastocysts attached to uterine epithelium early in implantation at E6.5, and at later time points of E5.5 and E6.0 (Fig. 3). The intensity of Mcl-1 expression was highest for the implanting blastocyst at E5.0 and was also strikingly prominent in the maternal decidua surrounding the embryo (Fig. 3a). The intensity of the Mcl-1 signal within the embryo itself decreased as development proceeds beyond E5.5 (Fig. 3b) to E6.5 (Fig. 3c). In contrast, expression in the decidua intensifies and narrows to the stromal cells proximal to the embryo (Fig. 3c). Thus, the expression pattern of Mcl-1 is consistent with a gene critical at the peri-implantation stage.

Because $\mathrm{Mcl}-1$ is expressed in both TE and ICM, it was uncertain whether either or both were responsible for the failure of Mcl-1 null embryos to implant in utero. In vitro culture of whole blastocysts can clarify peri-implantation lethal phenotypes (Fassler and Meyer 1995; Stephens et al. 1995). Consequently, blastocysts from Mcl-1 $1^{+/-}$matings were cultured on murine embryonic fibroblast (MEF) feeder layers or vitronectin-coated microdrop cultures. Regardless of the substratum, Mcl-1 null blastocysts failed to hatch from the zona pellucida or attach to the substrate (Table 1).

To assess whether Mcl-1 null embryos display a growth disadvantage in culture, two- to four- or eightcell-stage embryos from heterozygous matings were plated. Of these embryos, $66 \%$ progressed to the blasto-

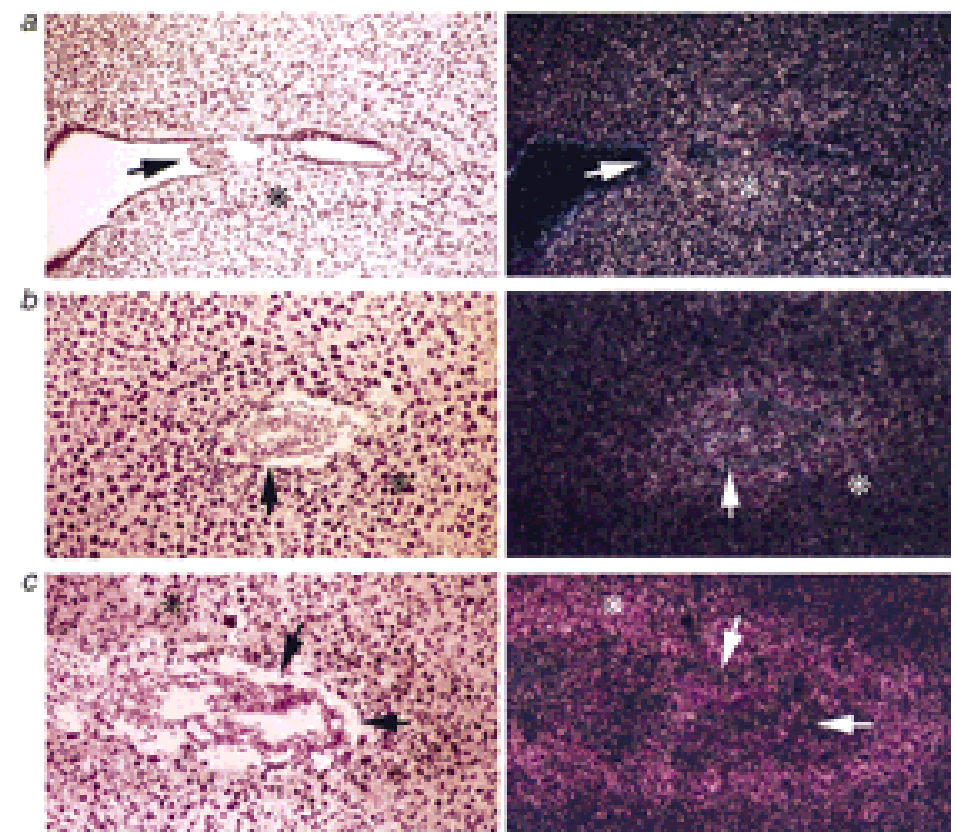

Figure 3. Mcl-1 RNA in situ hybridization of peri-implantation wildtype embryos. (a) Light- and dark-field images of E5.0 implanting blastocyst hybridized with the Mcl-1 antisense probe. (b) Light- and dark-field images of E5.5 implantation site. (c) Light- and dark-field images of E6.5 implantation site. Arrow points to ICM of implanting embryo. Maternal decidua is marked with an asterisk in $b$ and $c$. Magnification, 100x. cyst stage, and $88 \%$ of those attached and grew when replated onto a vitronectin substrate. However, none of the embryos that progressed to the blastocyst stage were Mcl-1 $1^{-/-}$indicating the development of nulls was arrested during in vitro culture.

The failure of Mcl-1 null embryos to hatch or attach in vitro indicates that the TE may be defective. Culturing isolated ICM can likewise provide an estimate of whether embryonic progenitor cells are able to develop postimplantation. Isolated ICM were obtained following immunosurgical removal of the TE (Behrendtsen and Werb 1997) plated on fibronectin and cultured for 5 days. A few $M c 1-1^{-1-}$ ICMs did attach and begin to develop as documented in Figure 4. Of 34 total ICMs from $\mathrm{Mcl}-1^{+/-}$ matings, 26 grew on the substrate, 2 were $M c l-1^{-1-}(8 \%)$, 14 were $+/-(54 \%)$, and 7 were $+/+(27 \%)$, whereas 3 $(12 \%)$ could not be genotyped. The capacity of $\mathrm{Mcl}-1$ null ICM to develop in vitro, even though perhaps impaired, indicates that the embryonic portion of the blastocyst may be less dependent on Mcl-1 than the TE. Complementation by tetraploid aggregation (Guillemot et al. 1994) was not feasible because of the limited Mcl-1 null embryos that survive preimplantation development and their impaired in vitro culture.

To determine whether the developmental potential of Mcl-1 null embryos was limited as a consequence of increased apoptosis, we modified the TUNEL assay for use on free-floating blastocysts that could be subsequently harvested for nested PCR genotyping. Several different approaches have estimated that $10 \%$ of cells of the ICM and TE of an E4.0 unhatched blastocyst ( 64 cell stage) are undergoing apoptosis (El-Shershaby and Hinchliffe 1974; Handyside and Hunter 1986). The average number of TUNEL-positive cells per embryo did not vary substantially for $7 \mathrm{Mcl}-1^{-/-}(2.6 \pm 2.2$ TUNEL-positive cells per blastocyst), $42 \mathrm{Mcl}^{-1^{+/-}}$ $(2.3 \pm 2.6)$, or $20 \mathrm{Mcl}-1^{+/+}(3.3 \pm 2.7)$ embryos. None of the Mcl-1 null embryos displayed $>10 \%$ apoptotic cells. In support of the TUNEL assay, DAPI and bis-benzimide staining revealed normal nuclear architecture and no increase in apoptotic cells in Mcl-1 null embryos. These results indicate that Mcl-1 deficiency does not result in catastrophic apoptosis at the last time embryos can be isolated from the uterus, $\sim 24 \mathrm{hr}$ prior to implantation. We cannot exclude massive cell death after that time point, including the induction of apoptosis in the trophectoderm upon contact with the uterine epithelium. However, the introduction of p53 deficiency did not rescue the $\mathrm{Mcl}-1$ nulls as it had for Mdm2 (Jones et al. 1995; Montes de Oca Luna et al. 1995) and rad51 (Lim and Hasty 1996) nor did the introduction of Bax deficiency (Knudson et al. 1995), which eliminated that proapoptotic molecule.

The Mcl-1 null phenotype is a combination of an embryonic developmental delay and an implantation defect so severe that there is no maternal decidualization. The peri-implantation lethality from knockouts of proliferation and DNA repair genes 

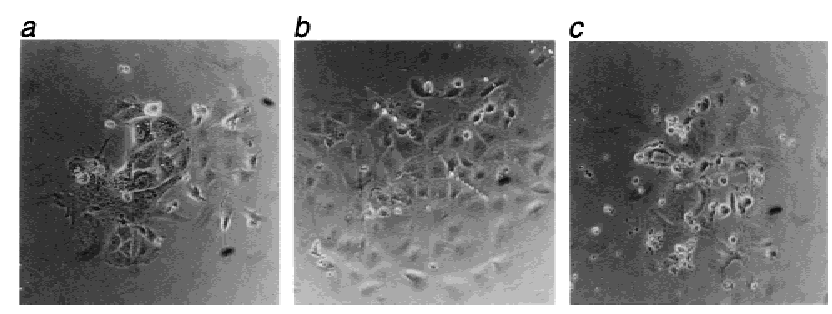

Figure 4. Light microscope images of inner cell mass outgrowths 5 days after immunosurgery and culture on fibronectin. Outgrowths were genotyped as $\mathrm{Mcl-1}^{+/+}(\mathrm{a}), \mathrm{Mcl}_{-1}{ }^{+-}(\mathrm{b})$, and Mcl-1-1- (c). Magnification, 200×.

varies in that Mdm2 (Jones et al. 1995; Montes de Oca Luna et al. 1995), Brca1 (Hakem et al. 1996; Liu et al. 1996), Rad51 (Lim and Hasty 1996), Ref-1 (Xanthoudakis et al. 1996), and thioredoxin (Matsui et al. 1996) all show empty decidua or degrading embryos. E-cadherin (Larue et al. 1994; Riethmacher et al. 1995) and $\alpha$ E-catenin (Torres et al. 1997) null embryos arrest as morula unable to form a blastocoel cavity. Although Mcl-1 does not appear to be required for TE to be distinguished from ICM, the Mcl-1-deficient embryos are defective at multiple steps required for successful embryonic development. The inability of the TE of null blastocysts to attach and the delayed maturation beyond the noncompacted blastomere stage for others, suggest that Mcl-1 null embryos are ill suited for the uterine environment. In addition to $\mathrm{Mcl}-1$, it is remarkable how many $B c \mathrm{l}-2$ family knockouts display infertility with $B a x$ (Knudson et al. 1995) and Bcl-w (Print et al. 1998; Ross et al. 1998) nulls demonstrating aspermatogenesis, whereas $\mathrm{Bcl}-2$ deficients (Ratts et al. 1995) have decreased numbers of oocytes. As many as $65 \%$ of natural pregnancies terminate during the peri-implantation period (Wilcox et al. 1988). These results indicate that Mcl-1 is a critical determinant for the success of this highly vulnerable stage of embryonic development.

\section{Materials and methods}

\section{Construction of an Mcl-1 gene targeting vector}

129Sv/J genomic phage clones were identified using a murine Mcl-1 cDNA probe. Clones were restriction mapped and partially sequenced. The targeting vector's 5' arm of homology included part of the 5' UTR. A 500-bp SacII-SacI fragment that included most of exon 1 and the translation start site of the Mcl-1 gene was deleted and replaced with the neomycin drug-resistance gene driven by the phosphoglycerate kinase gene promoter. The $3^{\prime}$ arm of homology contained the remainder of exon 1 through intron 2 (Fig. 1A). The construct was electroporated into the RW4 ES cell line and homologous recombinant clones microinjected into C57BL/ 6 blastocysts.

An Mcl-1 external probe located outside of the targeting construct was designed to distinguish germ line from homologous recombinant alleles and included the last $117 \mathrm{bp}$ of $\mathrm{Mcl}-1$ coding sequence from exon 3 as well as $165 \mathrm{bp}$ of the $3^{\prime}$ UTR. The internal probe consisted of base pairs 508-847 from the cDNA, a portion of exon I present in the targeting vector.

\section{PCR genotyping}

Pre- and postimplantation embryos were genotyped with nested sets of primers. The sequence of the first primer set for the wild-type allele was JR26, 5'-aaaggcggctgcataagtcg-3', and JR27, 5'-aagtagcgcgagatgatctccagc$3^{\prime}$. The second set of wild-type allele primers was JR28, 5'-gaggaggaactg- gacggctg-3', and JR29, 5' -cgactggcggtataggtcgtc- $3^{\prime}$. The first set of rearranged allele primers was JR23, 5' -taccegcttccattgctcag- $3^{\prime}$, and JR24, 5'tataggtcgtcctcttcctcctcg- $3^{\prime}$. The second set of rearranged allele primers was JR25, 5'-tgctacttccatttgtcacgtcc-3', and JR30, 5'-tggagggcagagagccgtc- $3^{\prime}$. The PCR product obtained after 32 cycles using the second sets of primers yielded fragments of the following sizes: wild-type allele, $168 \mathrm{bp}$, and rearranged allele, $350 \mathrm{bp}$.

\section{RNA in situ hybridization}

Hybridization was performed on frozen (OCT) and paraffin-embedded tissue that had been preserved in $4 \%$ paraformaldehyde/PBS solution for $12-20 \mathrm{hr}$ at $4^{\circ} \mathrm{C}$ (Wilkinson and Nieto 1993). Preimplantation embryos were fixed at room temperature for $30 \mathrm{~min}$ before OCT embedding. Slides were dipped twice in $0.1 \%$ gelatin solution and air-dried to prevent blastocyst sections from detaching during hybridization. Antisense and sense controls of the external Mcl-1 probe were hybridized to tissue sections that were exposed to photographic emulsion for 7-21 days before development.

\section{TUNEL analysis}

Blastocysts were fixed in $4 \%$ paraformaldehyde/PBS for $30 \mathrm{~min}$ at room temperature followed by two washes in 3\% BSA in PBS for 5-10 min each. The TACs 2 Tdt-based TUNEL assay kit (Trevigen) instructions were followed with the following exceptions: (1) The blastocysts were not fixed onto a slide to enable them to be collected individually for PCR analysis but, instead, were transferred between watchglasses (Thomas Scientific) containing reagent solutions; (2) proteinase K was not required; and (3) the TACsBlue stain was used to visualize apoptotic cells without counterstain to avoid embryo shrinkage. At the end of the assay, all embryos were transferred to a drop of distilled water under mineral oil and were photographed from multiple orientations to assure the visualization and counting of all blue-labeled apoptotic nuclei. After photography, individual embryos were collected for PCR analysis.

Inner cell mass culture

Immunosurgery and ICM culture were performed as described (Behrendtsen and Werb 1997).

\section{Acknowledgments}

This work was supported by CA49712-10. J.R. was supported by the American Cancer Society Postdoctoral Fellowship, grant PF-4228.

The publication costs of this article were defrayed in part by payment of page charges. This article must therefore be hereby marked "advertisement" in accordance with 18 USC section 1734 solely to indicate this fact.

\section{References}

Behrendtsen, O. and Z. Werb. 1997. Metalloproteinases regulate parietal endoderm differentiating and migrating in cultured mouse embryos. Dev. Dyn. 208: 255-265.

Bodrug, S.E., C. Aime-Sempe, T. Sato, S. Krajewski, M. Hanada, and J.C. Reed. 1995. Biochemical and functional comparisons of Mcl-1 and Bcl-2 proteins: Evidence for a novel mechanism of regulating Bcl-2 family protein function. Cell Death Differ. 2: 173-182.

Deckwerth, T.L., J.L. Elliott, C.M. Knudson, E.M. Johnson, Jr., W.D. Snider, and S.J. Korsmeyer. 1996. BAX is required for neuronal death after trophic factor deprivation and during development. Neuron 17: 401-411.

El-Shershaby, A.M. and J.R. Hinchliffe. 1974. Cell redundancy in the zona-intact preimplantation mouse blastocyst: A light and electron microscope study of dead cells and their fate. J. Embryol. Exp. Morphol. 31: 643-654.

Fassler, R. and M. Meyer. 1995. Consequences of lack of $\beta 1$ integrin gene expression in mice. Genes \& Dev. 9: 1896-1908.

Guillemot, F., A. Nagy, A. Auerbach, J. Rossant, and A.L. Joyner. 1994. Essential role of Mash-2 in extraembryonic development. Nature 371: 333-336.

Hakem, R., J.L. de la Pompa, C. Sirard, R. Mo, M. Woo, A. Hakem, A. Wakeham, J. Potter, A. Reitmair, F. Billia et al. 1996. The tumor suppressor gene Brcal is required for embryonic cellular proliferation in the mouse. Cell 85: 1009-1023. 
Handyside, A.H. and S. Hunter. 1986. Cell division and death in the mouse blastocyst before implantation. Wilhelm Roux's Arch. Dev. Biol. 195: 519-526.

Jones, S.N., A.E. Roe, L.A. Donehower, and A. Bradley. 1995. Rescue of embryonic lethality in Mdm2-deficient mice by absence of p53. $\mathrm{Na}$ ture 378: 206-208.

Knudson, C.M., K.S. Tung, W.G. Tourtellotte, G.A. Brown, and S.J. Korsmeyer. 1995. Bax-deficient mice with lymphoid hyperplasia and male germ cell death. Science 270: 96-99.

Kozopas, K.M., T. Yang, H.L. Buchan, P. Zhou, and R.W. Craig. 1993 MCL1, a gene expressed in programmed myeloid cell differentiation, has sequence similarity to BCL2. Proc. Natl. Acad. Sci. 90:35163520.

Krajewski, S., S. Bodrug, R. Gascoyne, K. Berean, M. Krajewska, and J.C. Reed. 1994. Immunohistochemical analysis of Mcl-1 and Bcl-2 proteins in normal and neoplastic lymph nodes. Am. J. Pathol. 145: 515525 .

Krajewski, S., S. Bodrug, M. Krajewska, A. Shabaik, R. Gascoyne, K. Berean, and J.C. Reed. 1995. Immunohistochemical analysis of Mcl-1 protein in human tissues. Differential regulation of $\mathrm{Mcl}-1$ and Bcl-2 protein production suggests a unique role for Mcl-1 in control of programmed cell death in vivo. Am. J. Pathol. 146: 1309-1319.

Larue, L., M. Ohsugi, J. Hirchenhain, and R. Kemler. 1994. E-cadherin null mutant embryos fail to form a trophectoderm epithelium. Proc. Natl. Acad. Sci. 91: 8263-8267.

Lim, D.S. and P. Hasty. 1996. A mutation in mouse rad51 results in an early embryonic lethal that is suppressed by a mutation in p53. Mol. Cell. Biol. 16: 7133-7143.

Liu, C.Y., A. Flesken-Nikitin, S. Li, Y. Zeng, and W.H. Lee. 1996. Inactivation of the mouse Brca1 gene leads to failure in the morphogenesis of the egg cylinder in early postimplantation development. Genes \& Dev. 10: 1835-1843.

Matsui, M., M. Oshima, H. Oshima, K. Takaku, T. Maruyama, J. Yodoi, and M.M. Taketo. 1996. Early embryonic lethality caused by targeted disruption of the mouse thioredoxin gene. Dev. Biol. 178: 179-185.

Montes de Oca Luna, R., D.S. Wagner, and G. Lozano. 1995. Rescue of early embryonic lethality in mdm2-deficient mice by deletion of p53. Nature 378: 203-206.

Motoyama, N., F. Wang, K.A. Roth, H. Sawa, K. Nakayama, I. Negishi, S Senju, Q. Zhang, S. Fujii and D.Y. Loh. 1995. Massive cell death of immature hematopoietic cells and neurons in Bcl-x-deficient mice. Science 267: 1506-1510.

Print, C.G., K.L. Loveland, L. Gibson, T. Meehan, A. Stylianou, N. Wreford, D. de Kretser, D. Metcalf, F. Kontgen, J.M. Adams, and S. Cory. 1998. Apoptosis regulator bcl-w is essential for spermatogenesis but appears otherwise redundant. Proc. Nat1. Acad. Sci. 95: 12424-12431.

Ratts, V.S., J.A. Flaws, R. Kolp, C.M. Sorenson, and J.L. Tilly. 1995 Ablation of bcl-2 gene expression decreases the numbers of oocytes and primordial follicles established in the post-natal female mouse gonad. Endocrinology 136: 3665-3668.

Reynolds, J.E., T. Yang, L. Qian, J.D. Jenkinson, P. Zhou, A. Eastman, and R.W. Craig. 1994. Mcl-1, a member of the Bcl-2 family, delays apoptosis induced by c-Myc overexpression in Chinese hamster ovary cells. Cancer Res. 54: 6348-6352.

Reynolds, J.E., J. Li, R.W. Craig, and A. Eastman. 1996. BCL-2 and MCL-1 expression in Chinese hamster ovary cells inhibits intracellular acidification and apoptosis induced by staurosporine. Exp. Cell. Res. 225: 430-436.

Riethmacher, D., V. Brinkmann, and C. Birchmeier. 1995. A targeted mutation in the mouse E-cadherin gene results in defective preimplantation development. Proc. Nat1. Acad. Sci. 92: 855-859.

Rinkenberger, J.L., J.C. Cross, and Z. Werb. 1997. Molecular genetics of implantation in the mouse. Dev. Genet. 21: 6-20.

Ross, A.J., K.G. Waymire, J.E. Moss, A.F. Parlow, M.K. Skinner, L.D. Russell, and G.R. MacGregor. 1998. Testicular degeneration in Bclwdeficient mice. Nat. Genet. 18: 251-256.

Stephens, L.E., A.E. Sutherland, I.V. Klimanskaya, A. Andrieux, J. Meneses, R.A. Pedersen, and C.H. Damsky. 1995. Deletion of $\beta 1$ integrins in mice results in inner cell mass failure and peri-implantation lethality. Genes \& Dev. 9: 1883-1895.

Torres, M., A. Stoykova, O. Huber, K. Chowdhury, P. Bonaldo, A. Mansouri, S. Butz, R. Kemler, and P. Gruss. 1997. An alpha-E-catenin gene trap mutation defines its function in preimplantation development.
Proc. Nat1. Acad. Sci. 94: 901-906.

Veis, D.J., C.M. Sorenson, J.R. Shutter, and S.J. Korsmeyer. 1993. Bcl-2deficient mice demonstrate fulminant lymphoid apoptosis, polycys tic kidneys, and hypopigmented hair. Cell 75: 229-240.

Welsh, A.O. 1993. Uterine cell death during implantation and early placentation. Microsc. Res. Tech. 25: 223-245.

Wilcox, A.J., C.R. Weinberg, J.F. O'Connor, D.D. Baird, J.P. Schlatterer, R.E. Canfield, E.G. Armstrong, and B.C. Nisula. 1988. Incidence of early loss of pregnancy. N. Engl. I. Med. 319: 189-194.

Wilkinson, D.G. and M.A. Nieto. 1993. Detection of messenger RNA by in situ hybridization to tissue sections and whole mounts. Methods Enzymol. 225: 361-373.

Xanthoudakis, S., R.J. Smeyne, J.D. Wallace, and T. Curran. 1996. The redox/DNA repair protein, Ref-1, is essential for early embryonic development in mice. Proc. Nat1. Acad. Sci. 93: 8919-8923.

Yang, T., K.M. Kozopas, and R.W. Craig. 1995. The intracellular distribution and pattern of expression of Mcl-1 overlap with, but are not identical to, those of Bcl-2. J. Cell. Biol. 128: 1173-1184.

Yang, T., H.L. Buchan, K.J. Townsend, and R.W. Craig. 1996. MCL-1, a member of the BLC-2 family, is induced rapidly in response to signals for cell differentiation or death, but not to signals for cell proliferation. J. Cell. Physiol. 166: 523-536.

Zha, J., H. Harada, E. Yang, J. Jockel, and S.J. Korsmeyer. 1996. Serine phosphorylation of death agonist BAD in response to survival factor results in binding to 14-3-3 not BCL-X(L). Cell 87: 619-628.

Zhou, P., L. Qian, K.M. Kozopas, and R.W. Craig. 1997. Mcl-1, a Bcl-2 family member, delays the death of hematopoietic cells under a variety of apoptosis-inducing conditions. Blood 89: 630-643.

Zhou, P., L. Qian, C.K. Bieszczad, R. Noelle, M. Binder, N.B. Levy, and R.W. Craig. 1998. Mcl-1 in transgenic mice promotes survival in a spectrum of hematopoietic cell types and immortalization in the myeloid lineage. Blood 92: 3226-3639. 


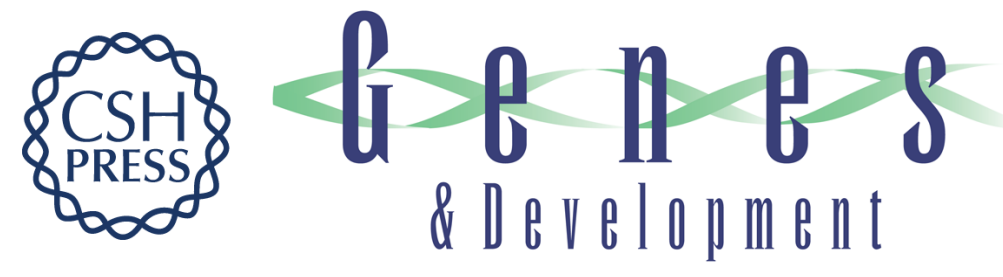

\section{Mcl-1 deficiency results in peri-implantation embryonic lethality}

Julie L. Rinkenberger, Susan Horning, Barbara Klocke, et al.

Genes Dev. 2000, 14:

Access the most recent version at doi:10.1101/gad.14.1.23

References This article cites 38 articles, 16 of which can be accessed free at: http://genesdev.cshlp.org/content/14/1/23.full.html\#ref-list-1

License

Email Alerting Receive free email alerts when new articles cite this article - sign up in the box at the top Service right corner of the article or click here.

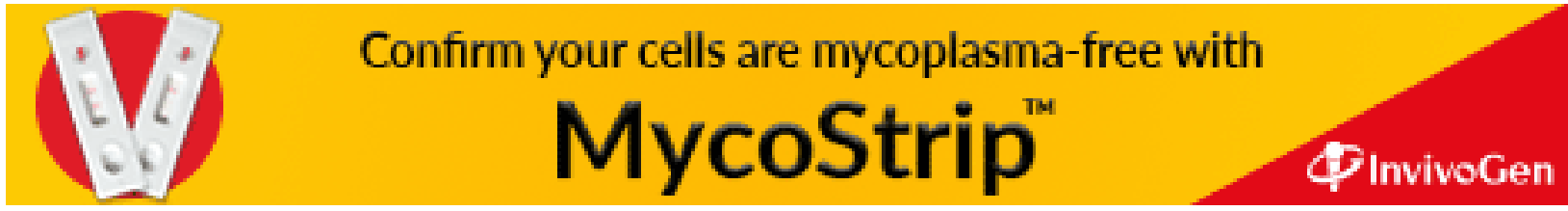

